\title{
Reflection on the effects of the severe acute respiratory syndrome due to coronavirus 2 pandemic
}

\author{
José A. Rojas-Ramírez ${ }^{1}$ and Octavio Amancio-Chassin ${ }^{2 *}$ \\ ${ }^{1}$ Department of Pharmacology, Faculty of Medicine, Universidad Nacional Autónoma de Mexico (UNAM); ${ }^{2}$ Pharmacovigilance Service, Institutional \\ Center for Pharmacovigilance, Hospital General de México "Dr. Eduardo Liceaga." Mexico City, Mexico
}

In December 2019, Dr. Li Wenliang, a young ophthalmologist at Wuhan Central Hospital in China, posted on social media the presence of seven patients with pneumonia similar to severe acute respiratory syndrome. In January 2020, variant 2 of this coronavirus was reported to be the causative agent of what is known as severe acute respiratory syndrome due to coronavirus 2 (SARS-CoV-2). On January 30, 2020, the Emergency Committee reaches consensus and recommends to the Director General that the outbreak constitutes a Public Health Emergency of International Concern (ESPII). The Director General accepts the recommendation and declares that the outbreak by the new coronavirus constitutes an ESPII and on March 11, the Health Organization (WHO) declared it a pandemic ${ }^{1}$. By April 28-29, 2020, the SARS-CoV-2 RNA genome had expanded in 210 countries and more than $3,000,000$ cases had been reported ${ }^{2}$. Until August 24, 212,357,898 confirmed cases and $4,439,843$ deaths have been reported worldwide, and in Mexico, there is a report of $3,225,073$ patients and 253,155 deaths $^{3}$.

This fact by itself is a reason for the attention of bioethics, raised from its origin, as the link between the application of scientific knowledge and ethical and moral principles in all areas of human activity. The effects of the spread of viral infection have impacted many aspects of the lives of individuals and societies. For example, to counteract its spread, sanitary measures were implemented that promoted the use of masks, frequent hand washing, and social isolation; in addition, the mobility of individuals in their communities, academic, work, recreational, political, commercial activities (only essential ones were allowed), tourism, and social gatherings of all kinds was restricted; that limited, above all, the freedom of people in the face of the activities proper and necessary of the communities of which they form part.

The impact of an epidemic depends on the number of people infected, the transmissibility of the infection, and the spectrum of clinical severity. In many countries, the impact of the pandemic has shown that health systems have been overwhelmed by the number of infections and patients with various serious conditions associated with secondary pathologies or poorly attended social conditions, such as the insufficient existence of hospitals, health centers, specialized clinics; the deficient acquisition of health supplies (ventilators, protective equipment, medicines, vaccines, and healing materials). In addition, comorbidities that favor infection (diabetes mellitus, high blood pressure, obesity and chronic obstructive disease); poor quality of diet (rich in calories, excess sodium, and saturated fat); and social inequality (access to different health systems, health medical expenses insurance).

On the other hand, biomedical and epidemiological research faces the challenge of providing adequate knowledge of SARS-CoV-2, such as: its origin, characteristics (classification, morphology, and structure), its transmission and pathogenesis; to develop and

\section{Correspondence:}

*Octavio Amancio-Chassin

E-mail: octaviorev28@gmail.com
Available online: 18-10-2021

Date of reception: $27-08-2021$ DOI: 10.24875/HGMX.M21000042
Rev Med Hosp Gen Mex. 2021;84(4):143-146

www.hospitalgeneral.mx

0185-1063/@ 2021 Sociedad Médica del Hospital General de Mexico. Published by Permanyer. This is an open access article under the CC BYNC-ND license (http://creativecommons.org/licenses/by-nc-nd/4.0/). 
implement an accurate, early, and inexpensive diagnostic test that allows timely implementation of sanitary measures that reduce the transmission of the viral infection to family members, coworkers, health personnel or the general population or discover a pharmacological treatment, and effective and efficient preventive measures to reduce the morbidity and mortality of coronavirus disease 2019 (COVID-19) disease.

In the case of the investigation of therapeutic and preventive agents, proposals have emerged based on anecdotal information or clinical trials with methodological defects (selection or measurement bias) and ethics with weakly conclusive results. Mainoli et al. searched the WHO International Trial Registry Platform and national trial registries for COVID-19 trials through April 19, 2020, for 580 trials evaluating the treatment against COVID-19, the quality of the reports was poor globally. In the trial protocols evaluating COVID-19 treatment, the maximum age of inclusion was not specified in 332 protocols $(57.2 \%)$, it was not reported whether the research subjects had severe disease 159 (27.4\%) or critical 197 (34.0\%). Most of the studies $67.9 \%$ used a randomized design, $58.3 \%$ were conducted in a single center, $47.6 \%$ would be conducted in China, and only $3.0 \%$ included centers from other countries. The median sample size was 100 participants (interquartile range 50-260 research subjects) and the duration of the trial was 184 days (interquartile range 94-365 days). The main endpoints (mortality, evolution of clinical status, and duration of hospitalization) were identified in very few trials (range 5.2-13.1\%)

Developing new drugs to treat COVID-19 effectively is a challenging and time-consuming process. It is clear that the bioethical implications are inescapable, pharmaceutical companies equipped with high technology have developed vaccines in short terms with the purpose of preventing or reducing the possibility of acquiring the infection or reducing the severity of those who become infected, where emergency approval by the health authority of the countries has been carried out with the information on safety, efficacy, and manufacturing quality, which is available to date.

The doses registered worldwide until August 24, 2021, are $4,619,976,274$, where $1,056,134,385$ people have a complete schedule and 1,799,362,166 subjects have one dose. In Mexico, the vaccination program begins on December 24, 2020; and until August 23 of this year, $30,219,721$ people have been vaccinated with a complete schedule, 55,643,238 with at least one dose, and
$79,399,398$ doses have been administered. However, there are some less favored nations that have not received the benefit of vaccination: Haiti, Nicaragua, Venezuela, Chad, Ethiopia, Mauritania, Vietnam, and Iraq $\left(\right.$ Table 1) ${ }^{3}$. Even though, on April 24, 2020, the world leaders agreed to join together to ensure access to vaccines, testing and treatment for COVID-19, prompting the WHO COVAX initiative for accelerated equitable access to vaccines globally. However, these data show how socioeconomic inequality between nations affects the development of countries to different degrees, promoting dependence, especially technological, from the least favored to the most developed and, perhaps, ethically selfishness, unacceptable.

On the other hand, the ethical commitment of health personnel to provide care under conditions that represent a risk to their own health is added. It is ethically acceptable to provide care and protection to patients; but also, it is to have the means and the due protection for the performance of their tasks. The pandemic has led to the development of ethical guidelines for the care of health personnel to the sick. However, in practice, health professionals are the ones who end up making decisions about patient care ${ }^{5}$.

Economic activity is one of the most affected areas, its consequences affected medium and small companies that have not been able to overcome the crisis and caused the loss of numerous jobs. In a review on the impact of COVID-19 on the economy, Mallah et al. noted that the annual report of the World Trade Organization estimates that the volume of world trade decreased overall by $9.2 \%$ in 2020 , due to the economic impact of the pandemic, that the world economy faced in 2020 the deepest recession since 1945 , with a contraction of $4.3 \%$ of world gross domestic product (GDP) and a decrease of $6.2 \%$ of world GDP per capita. The estimated cumulative cost of SARSCoV-2 on world economic output in 2020 and 2021 is USD 8.5 trillion and USD 22 trillion between 2020 and $2025^{6}$. The economic implications of the COVID-19 outbreak and the start of global economic growth toward recovery depend on the trajectory of the virus, the duration of the pandemic, and the success of vaccines ${ }^{6}$.

The social consequences are obviously the loss of close people in the family, work, or social environment, associated with the disruption of freedoms, personal attitudes, fear of contagion, and uncertainty in the face of a threat, until now difficult to control. With the warning of not being the only ones, the WHO-GloPID COVID-19 5 World Research and Innovation Forum ${ }^{7}$ 
Table 1. List of countries according to the vaccination program against COVID-19

\begin{tabular}{|c|c|c|c|}
\hline \multirow[t]{2}{*}{ Country } & Total doses administered & Persons fully vaccinated & Persons vaccinated with at least one dose \\
\hline & \multicolumn{3}{|c|}{ Per 100 population } \\
\hline Canada & 138.21 & 65.17 & 73.04 \\
\hline United States of America & 109.12 & 51.40 & 61.97 \\
\hline Mexico & 61.58 & 23.44 & 43.16 \\
\hline Guatemala & 19.70 & 3.73 & 15.96 \\
\hline Nicaragua & 9.25 & 3.03 & 6.22 \\
\hline Honduras & 30.78 & 11.34 & 19.44 \\
\hline Haiti & 0.22 & 0.02 & 0.21 \\
\hline Brazil & 78.08 & 23.73 & 56.39 \\
\hline Peru & 50.47 & 21.97 & 28.5 \\
\hline Argentina & 84.40 & 24.68 & 59.73 \\
\hline Egypt & 6.33 & 2.11 & 4.22 \\
\hline Morocco & 81.82 & 34.98 & 46.84 \\
\hline Mauritania & 5.47 & 0.55 & 4.92 \\
\hline Ethiopia & 2.04 & 0.27 & 1.77 \\
\hline Chad & 0.24 & 0.08 & 0.16 \\
\hline South Africa & 16.80 & 7.56 & 9.24 \\
\hline Russia & 52.39 & 23.50 & 28.89 \\
\hline Vietnam & 8.28 & 0.84 & 7.44 \\
\hline India & 40.63 & 9.05 & 31.57 \\
\hline Afghanistan & 3.09 & 1.11 & 1.98 \\
\hline Iraq & 2.71 & 0.97 & 1.74 \\
\hline Israel & 146.82 & 62.86 & 68.05 \\
\hline Spain & 133.29 & 65.70 & 74.88 \\
\hline French & 127.49 & 56.66 & 72.33 \\
\hline Germany & 119.45 & 58.75 & 63.98 \\
\hline United Kingdom & 129.70 & 59.96 & 69.72 \\
\hline Bulgaria & 31.89 & 15.99 & 15.89 \\
\hline Bosnia Herzegovina & 28.29 & 11.0 & 17.29 \\
\hline New Guinea & 1.14 & 0.19 & 0.95 \\
\hline Australia & 53.82 & 18.24 & 35.72 \\
\hline
\end{tabular}

exposed the following ethical concepts that could be considered to deal with the pandemic in the field of research. They are presented in a summarized way and it is worth applying them in all areas:
1. Solidarity or recognition of the need of the other undoubtedly linked to justice, reciprocity, and empathy 2. Respect for others, treating them as morally equal, considering their dignity and autonomy 
3. Equity or fair treatment of all people according to their needs, without any discrimination

4. Autonomy, recognized principle in medical care and research and ideal in health care

5. Vulnerability which means undertaking a different ethical response to a person or a group of people who need it

6. Confidence in reference to people or institutions acting based on solid evidence.

Based on these principles, or by understanding and conviction, individuals and societies are faced with the challenge of reconciling the interests of some with those of others, in the fight for the mitigation of the pandemic. Bioethics must contribute to establish the border between the actions of the health authority (which seek the common good of the population) and the rights of individuals (where their autonomy and freedom are affected), an ethical dilemma that is difficult to resolve.

Although we still do not know how much more time will have to pass, we have to take advantage of the appearance and the work undertaken against this pandemic to discover a more equitable normality than the one in which we have been living and of which apparently, we had not realized or not. We wanted to acknowledge.

\section{Funding}

The authors declare have no commercial or financial relationship with any sponsor or direct professional relationship with it.

\section{Conflicts of interest}

The authors declare that they have no conflicts of interest.

\section{Ethical disclosures}

Protection of human and animal subjects. The authors declare that no experiments were performed on humans or animals for this study.

Confidentiality of data. The authors declare that no patient data appear in this article.

Right to privacy and informed consent. The authors declare that no patient data appear in this article.

\section{References}

1. Declaración Sobre la Segunda Reunión del Comité de Emergencias del Reglamento Sanitario Internacional (2005) Acerca del Brote del Nuevo Coronavirus (2019-nCoV). 30 de enero 2020, Ginebra Suiza. Available from: https://www.who.int/news/item/30-01-2020-statement-on-the-second-meeting-of-the-international-health-regulations-(2005)-emergency-committee-regarding-the-outbreak-of-novel-coronavirus-(2019-ncov) [Last accessed on 2021 Aug 03].

2. Mojica-Crespo R, Morales-Crespo MM. Pandemia COVID-19, la nueva emergencia sanitaria de preocupación internacional: una revisión. Semergen. 2020;46:72-84.

3. World Health Organization. WHO Coronavirus (COVID-19) Dashboard. Available from: https://www.covid19.who.int;revised [Last accessed on 2021 Aug 24]

4. Mainoli B, Macado T, Duarte GS, Prada L, Goncalves N, Ferreira JJ, et al. Analysis of clinical and methodological characteristics of early COVID-19 treatment clinical trials: so much work, so many lost opportunities. BMC Med Res Methodol. 2021;21:42-51.

5. Lewis J, Schuklenk U. Bioethics met its COVID-19 Waterloo: the doctor knows best again. Bioethics. 2020;35:3-5.

6. Dawson A, Emanuel EJ, Parker M, Smith MJ, Voo TC. Key ethical concepts and their application to COVID-19 research. Public Heath Ethics. 2020;13:127-32.

7. Mallah SI, Ghorab OK, AI-Salmi S, Abdellatif OS, Tharmaratnam T, Iskandar MA, et al. COVID-19: breaking down a global health crisis. Ann Clin Microbiol Antimicrob. 2021;20:35. 